\title{
Replication of the TOSTAN Programme in Burkina Faso: How 23 villages participated in a human rights-based education programme and abandoned the practice of female genital cutting in Burkina Faso
}

\author{
Nafissatou J. Diop \\ Population Council \\ Edmond Bagde \\ Population Council \\ Djingri Ouoba \\ Molly Melching
}

Follow this and additional works at: https://knowledgecommons.popcouncil.org/departments_sbsr-rh

Part of the Community-Based Learning Commons, Community-Based Research Commons, Gender and Sexuality Commons, International Public Health Commons, Maternal and Child Health Commons, Public Health Education and Promotion Commons, and the Women's Health Commons How does access to this work benefit you? Let us know!

\section{Recommended Citation}

Diop, Nafissatou J., Edmond Bagde, Djingri Ouoba, and Molly Melching. 2003. "Replication of the TOSTAN Programme in Burkina Faso: How 23 villages participated in a human rights-based education programme and abandoned the practice of female genital cutting in Burkina Faso." Dakar: Population Council. 


\section{How 23 Villages Participated} in a Human Rights-based

\section{Education Programme and Abandoned the Practice of Female Genital Cutting in Burkina Faso}
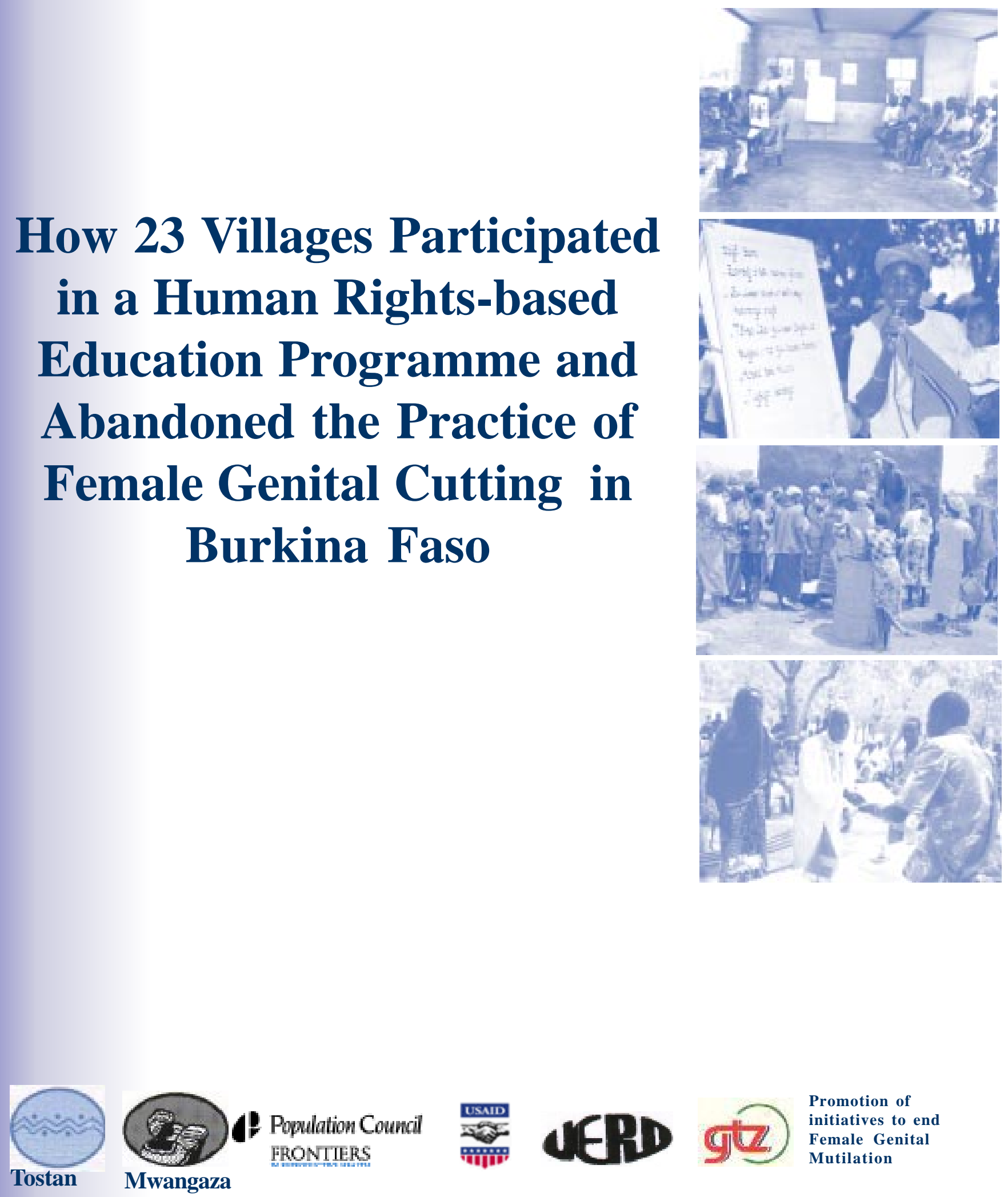


\title{
Replication of the TOSTAN Programme in Burkina Faso
}

\author{
How 23 Villages Participated in a Human Rights-based \\ Education Programme and Abandoned the Practice of \\ Female Genital Cutting in Burkina Faso
}

\section{Population Council}

Dr Nafissatou J. Diop

Edmond Badge

\section{Mwangaza Action}

Djingri Ouoba

\section{TOSTAN}

Molly Melching

April 2003

This study was financed by the United States Agency for International development (USAID) under the Cooperation Agreement number HRN-A-98-0012-00, and the Promotion Project for the Initiatives for Eradication of Female Genital Cutting, in collaboration with GTZ (Promotion of initiatives to end Female Genital Mutilation). The opinions expressed in this document are those of the writers and do not necessarily reflect the views of USAID 


\section{SUMMARY}

The improvement of women's reproductive health and welfare has been one of the top priorities at international level in recent years. As a result, the Government of Burkina Faso is committed to the improvement of reproductive health in general, and specifically to the abandonment of Female Genital Cutting (FGC).

Within this context, the Population Council initiated a collaboration between two NGOs, Tostan in Senegal and Mwangaza Action in Burkina Faso, to replicate the Tostan community-based education programme for improving women's reproductive health and contributing to the end of FGC. This programme was developed by Tostan in collaboration with UNICEF Senegal over a 15-year period and includes four modules with 64 sessions covering human rights education, the problem-solving process, hygiene and women's health. The participants (men and women) hold discussions to analyze the problems faced by their communities and to find appropriate solutions. In Senegal the programme culminated in a series of 16 public declarations for the abandonment of FGC and early marriage in 1,271 communities, between July, 1997 and December, 2003.

In Burkina Faso, the community-based education programme involved 23 villages in the Zoundwéogo Province in the districts of Béré and Bindé. During the implementation of the Tostan programme by Mwangaza Action, many positive changes occurred in the participating villages. The communities now promote reproductive health and human rights and hold regular clean up activities for improving public hygiene. Also, these villages are now standing up against violence towards women. The utilization of health services, antenatal care, family planning and child health have significantly increased. The programme has improved the population's knowledge in general and changed their views on women's roles in community development activities.

At the end of the programme, the 23 communities made a public declaration for the abandonment of the practice of FGC in front of 5,000 villagers, religious, traditional and political leaders, the media and programme managers from government, NGOs and international organizations.

This document is a summary of the entire process followed in implementing the programme. It was written to help in the replication of the TOSTAN programme in other social and cultural contexts similar to that of Burkina Faso. 


\section{Table Contents}

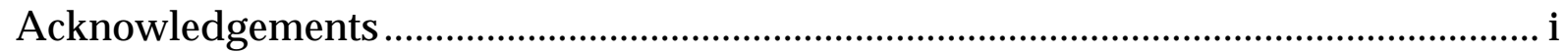

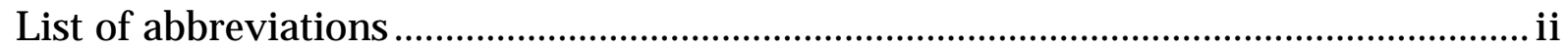

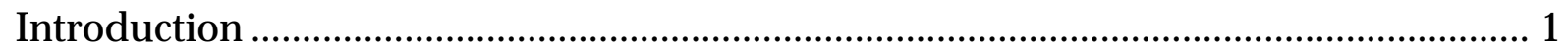

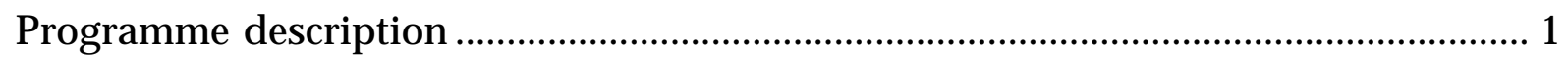

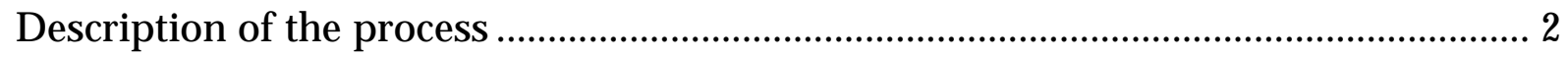

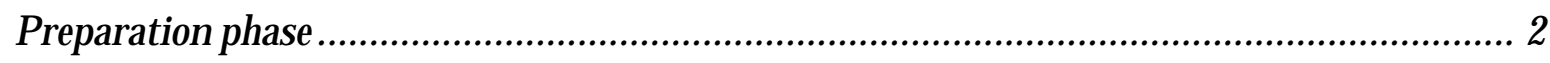

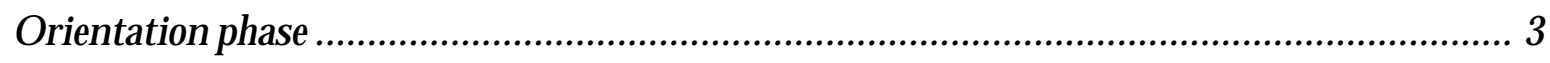

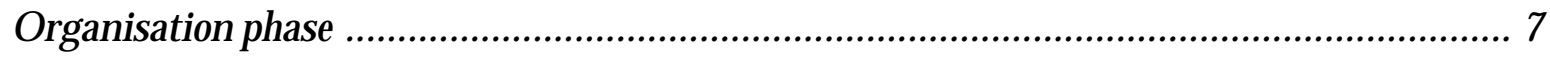

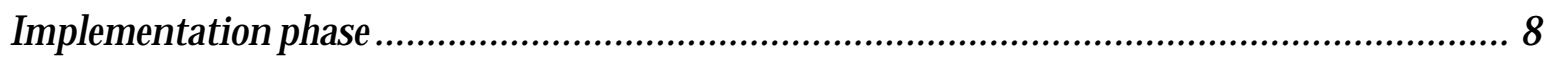

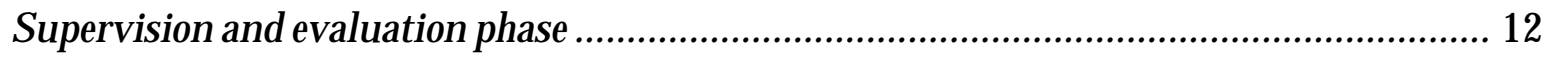

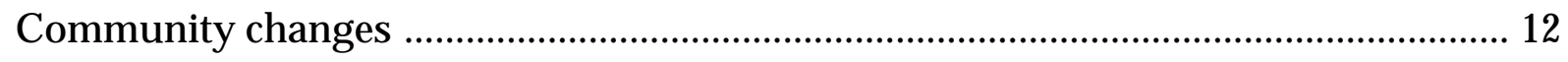

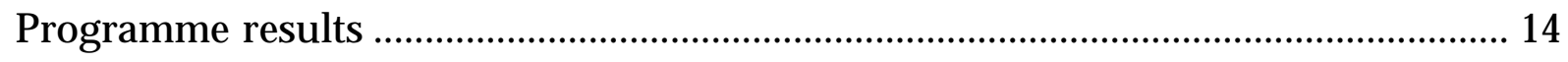

Agreement of 23 villages witnessed by 5000 people .................................................. 15

Underlying factors for social change in the Béré and Bindé communities ........................ 17

What can be learnt from such a collective agreement? ................................................... 18

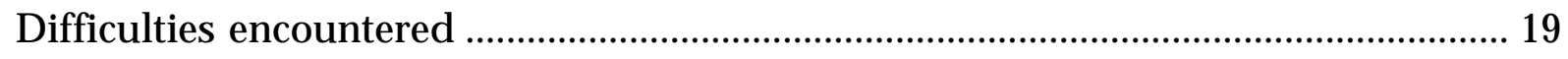

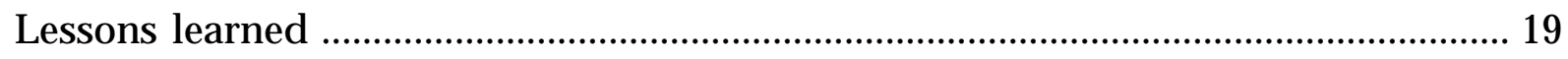

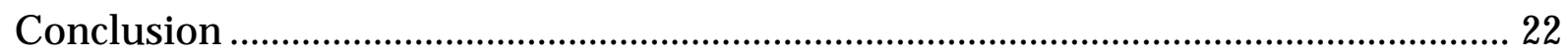




\section{ACKNOWLEDGEMENTS}

Mwangaza Action extends its acknowledgements to all those who supported it technically and financially in the implementation of the Tostan community based education programme: the National Committee for the Fight Against Female Genital Cutting, the TOSTAN NGO, Population Council's FRONTIERS Programme, USAID, and GTZ (Promotion of Initiatives for Ending Female Genital Cutting).

We would like to express our sincere thanks to Dr. Nafissatou Diop who first envisioned the collaboration between Mwangaza Action, Tostan, Population Council and GTZ and greatly contributed to making the partnership a success.

We thank TOSTAN, without whom this whole experience would not have taken place. TOSTAN graciously provided Mwangaza Action with their curriculum and all the educational materials necessary for the implementation of the programme. TOSTAN also provided the training and education for the staff of Mwangaza Action throughout the programme.

We also express our gratitude to Dr. Inge Baumgarten and Mrs. Pascaline Sebgo, who encouraged us to document this experience.

The programme would not have been successful in the field without the dedicated and combined effort of all our development partners, including the village facilitators, the communities, the supervisors and the coordinators. We express our appreciation to everyone. We hope that this report adequately reflects their tireless efforts.

We also thank the people in the district of Béré and Bindé in the Zoundwéogo Province. Their hospitality and their participation were instrumental to the success of the project.

Our gratitude also extends to the administrative authorities and the community leaders in the intervention area for their support and involvement in implementing the programme.

Finally we would like to thank Mr Edmond Badgé for his feedback and contribution to the preparation of this document. 


\section{List of Abbreviations}

MCHT Management Committees for Health Training

ICPD International Conference on Population and Development

HSAC Health and Social Advancement Committee

VMC Village Management Committee

FGC Female Genital Cutting 


\section{INTRODUCTION}

The 1994 International Conference on Population and Development (ICPD) held in Cairo, Egypt brought new emphasis on the importance of reproductive health. The 174 participating countries made an international commitment to the improvement of reproductive health and to the protection of reproductive rights in their respective countries.

The goal of the reproductive health policy is to improve the health and well being of world populations. Reproductive health is seen as an important right for men, women, adolescents and young children because it has an impact on long term human development.

In order to contribute to the improvement of sexual and reproductive health, Mwangaza Action replicated the Tostan community-based education programme in 23 villages from the Zoundwéogo Province in Burkina Faso. TOSTAN developed their curriculum and training programme in Senegal in collaboration with UNICEF over a 15 year period. The programme was implemented in more than 1,000 communities in Senegal from July, 1997 through December, 2003 and resulted in 16 public declarations for the abandonment of Female Genital Cutting by 1,271 Senegalese communities

The community-based education programme stands out among a range of development programmes in Burkina Faso because of the emphasis it places on Human Rights education and reproductive health. with the aim of ending violence against women, and FGC in particular.

The programme was financed by USAID through the FRONTIERS Programme of the Population Council, and by GTZ through its Regional Project Aimed at the Abandonment of FGC.

\section{Programme Description}

The goal of the TOSTAN community-based education programme implemented by Mwangaza Action in Burkina Faso was to contribute to the improvement of reproductive health in Béré, Bindé and Sondré zones in the health district of Manga, Zoundwéogo Province. The programme aimed to provide decision makers, donors, directors of associations and NGOs with an initiative to reinforce the national health programme and contribute to the elimination of FGC in Burkina Faso.

The specific objectives were:

a) To empower participants through education in human rights, the problem solving process, hygiene and women's health.

b) To actively engage the populations of these zones in reproductive health issues by organizing meetings and public discussions.

To achieve these objectives and attain the expected programme outcome, both men and women would acquire:

- An understanding of human rights and how they can be applied to improve living conditions

- Skills for solving family and community problems

- Technical information relating to hygiene and disease prevention

- Knowledge about the development and functions of the human body

- Information on the methods of promoting health at each stage of the development of the human body

- Knowledge of traditional practices that are harmful to health and the strategies to end them 
- Communication skills to effectively share information with other members of the community and other villages in the zone

- Motivation to undertake research in order to find common solutions to problems facing the village

- Renewed confidence in their ability to initiate positive social change.

Five aspects characterize this community-based education programme:

- A Human Rights and responsibilities approach

- Significant participant input in all aspects of the programme

- Sponsorship systems, where each member of the class adopts one person from his/her community to share the information received during the class session, and the class adopts other villages

- Facilitators become development agents: the facilitators are based in participating villages and become part of the community

- The programme has two parts: implementation and an action-research component

The TOSTAN education package consists of four modules:

- Human Rights: In this module, participants learn about the human rights guaranteed in international documents, their right to health, right to protection against all forms of violence and discrimination and right to education. The new understanding gained in this module serves as an empowering foundation for the remaining themes and is constantly referred to throughout the programme.

- The Problem-Solving Process: Participants learn a generic process for problem solving that helps them better identify and analyze their own problems related to human rights and responsibilities, health, the environment and project implementation. This process helps them find solutions appropriate to their situation and to implement them on an individual, family and community level.

- Basic Hygiene Participants understand the importance of personal and community hygiene by learning about germ transmission and the benefits of prevention over the costs of treatment. Participants immediately apply their new problem-solving skills for the improvement of community hygiene problems.

- Women's Health Through open and honest dialogue, participants gain information to improve women's physical and mental health in the community. Focusing on the importance of respecting women's human rights, participants talk about their bodies and reproduction, healthy development and illnesses affecting women and girls. Participants also weigh the merits of certain positive traditional practices (breastfeeding and infant massage) against the dangers of others such as early marriage and FGC.

These four were implemented over an 18 month period in the 23 villages.

\section{DESCRIPTION OF THE PROCESS}

Five phases were followed during the project: preparation, orientation, organization, implementation and evaluation.

\section{Preparation phase}

The programme which Mwangaza Action implemented in Burkina Faso was developed by the Senegalese NGO, TOSTAN. This first phase revolved around identifying TOSTAN programme activities that would be implemented by Mwangaza Action. Several other activities were also carried out: 


\section{i) Translation of the educational materials}

The different documents used during the four-module TOSTAN programme were translated into the Moore language. These include Guide Number 1 on Human Rights and Problem-solving and Guide Number 2 on Hygiene and Women's Health, as well as flip charts and other documents that accompany the modules.

\section{ii) Establishing the training teams}

The Burkina Faso training team was composed of two representatives from Mwangaza Action and three supervisors.

This team spent a month in Thiés, Senegal learning about the TOSTAN programme and sharing experiences with their Senegalese counterparts. This gave the Burkinabé trainers a better understanding of the community-based education programme and helped them to adapt it to the Burkina Faso context.

The Burkina Faso team had the opportunity to participate in a public declaration for the abandonment of FGC in 285 villages held in Karcia (Kolda Region) in Senegal. This gave them the opportunity to become fully aware of the organizational process involved in these ceremonies and to experience first hand the nuihlis declaration for FGC

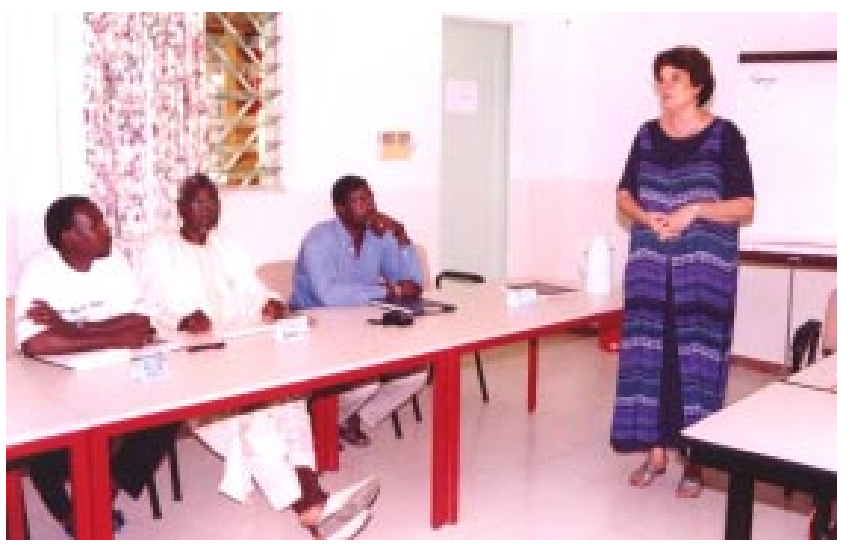

Training the trainers at Thiés, Senegal. Standing is Molly Melching, Director of the TOSTAN

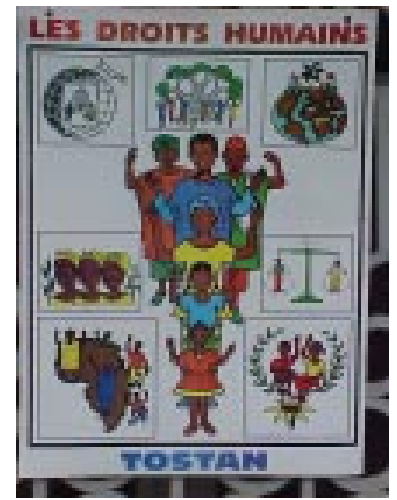
nent.

\section{Ition phase}

: members of the Burkina Faso training team returned, they began organizational and presented the community-based education programme to the different partners $s$ involved in project implementation.

ent steps of this phase included:

\section{ment of community facilitators}

I wentu-ınree community facilitators were recruited, based on the following criteria: level of education (high school graduate and above), language skills (competence in the national language - Moore) and commitment to working in a rural environment. This group of 13 women and 10 men worked from December 2000 to June 2001. The long pause in programme activities during the rainy season led 12 community facilitators to drop out. They were replaced by 12 new facilitators who worked from October 2001 to March 2002.

Because the training of human resources is an essential aspect in the process of consolidating people's potential, it would be preferable to guarantee employment of the programme personnel for the full duration of the programme implementation in order to guarantee a continuation of activities. Any interruption can lead to the departure of personnel to look for other opportunities, which is detrimental to the programme because more recruitment and training has to be undertaken. 
ii) Information and orientation for the community facilitators on programme content and approach

A two-day workshop was organized for the community facilitators with three objectives:

- To provide an orientation on the community-based education programme with a clear vision of programme content and of Mwangaza's role in project implementation

- To prepare the facilitators for their initial visit to the rural communities

- To orient the facilitators on how to present the programme to the communities.

The workshop provided an opportunity for team members to get to know one another well. Participants included those responsible for implementation of the programme as well as community facilitators, supervisors and coordinators. The workshop utilized active training techniques with team-building exercises to reinforce unity and team spirit among all the actors in the programme.

\section{iii) Facilitators three-week visit to rural communities}

In order to prepare for their new role in supporting the community and creating an environment of mutual understanding, the 23 facilitators visited one of the participating communities for a three-week stay. This was an excellent opportunity for the newly recruited community facilitators to learn about community lifestyle, traditions and values. The objectives of the visit were the following:

- To establish trust with the community and its leaders and begin a relationship with the people;

- To get to know the local populations where the programme intervention would take place, the different local authorities and individuals as well as other development agents working in the area;

- To gain better geographical knowledge of the project area and to help the facilitators to become integrated within the new environment;

- To collect basic information on the community, including maternal and neonatal health, in order to establish the pre-intervention situation of the village.

After discussions and negotiation with village leaders, the facilitators settled into the community in a family or a room proposed by the community.

During their three-week stay, the facilitators became acquainted with the different actors in the community (health personnel, members of the health management committee, village administrative leaders, village chiefs, influential persons, religious and other leaders and members of men and women's groups) to better understand community organization and structures. The work method used during this immersion period was:

a) Observation of daily life and participation in village activities

b) Interviews and communication with the different target groups identified within the community

At the end of the three-week stay in the villages, the facilitators had greatly benefited from the visit in terms of:

a) Knowledge of the population (organization, practices, habits and customs)

b) Understanding of the community worldview

c) Knowledge of the language and vocabulary used in the community

d) Better understanding of the different lifestyle

e) Beginning of a basic understanding of community needs and objectives in relation to the goals of the community based education programme. 
The immersion stay allowed the communities and the facilitators to build relationships based on mutual trust, respect for others and the sharing of responsibilities.

\section{iv) Informal meetings with local administrative officials and development agents}

Informal meetings were organized with administrative officials (General Secretary of the Zoundwéogo Province, and the chief administrative officers in Béré and Bindé districts) the heads of the technical development services (Provincial head of the Ministry of Social Action and National Solidarity, District Chief Medical Officer), the heads of the local health clinics, health management committees, the village administrative leaders, as well as the traditional leaders (district or area chiefs), religious leaders and other people of influence in the project area.

These meetings consisted of informal discussions explaining programme objectives and strategies for their implementation. They ended with plans for future meetings to include a wider spectrum of leaders and community representatives.

\section{v) Discussion about the programme with village representatives}

Further meetings brought together community leaders from each village, including members of the Health Centre Management Committees at the level of the Centres for Health and Social Welfare. The following people also took part in the meetings:

- Community health agents

- Religious leaders

- Traditional chiefs

- Village administrative officials

- Members of the health centre management committees

- Health agents of the Centres

- The heads of technical services (basic education, environment, agriculture etc)

- Leaders of village groups

- NGO directors

- Local government authorities

\section{Responsibilities of each community}

- Welcome and accommodate the community facilitator.

- Determine a place and / or construct a shelter to serve as a classroom.

- Put in place a management committee.

- Identity the audiences.

- Manage the material and the supplies.

- Encourage the participation of women.

- Look after the classroom.

- Create a framework for exchange between the participants in the education programme and in the community.

- Use the basic skills for positive action in the community.

Responsibilities of Mwangaza Action

- To ensure the training of the community facilitator.

- To ensure the implementation of the programme by placing a facilitator at the disposition of each village to start of the classes, the follow-up and the evaluation of the education programme.

- To put at the community's disposal all material and supplies necessary for the class activities.

- To ensure the implementation of the research aspect of the programme in collaboration with other partners with the goal of documenting the process.

Altogether, 144 people participated in three meetings. The discussions centered around the programme goals, objectives, content, strategies, and the roles and responsibilities of the different partners (Mwangaza Action and the community). 
These discussions were introduced by a short skit that focused on potential results of the community-based education programme. The skit is an active technique that encourages a lively exchange of ideas by everyone.

The community leaders and members asked questions to clarify how they could adapt the programme contents to their specific situation. The task assigned to the participants was to report back to their respective neighbourhood on the content and discussion during the meeting. This is related to the first step in the strategy: to

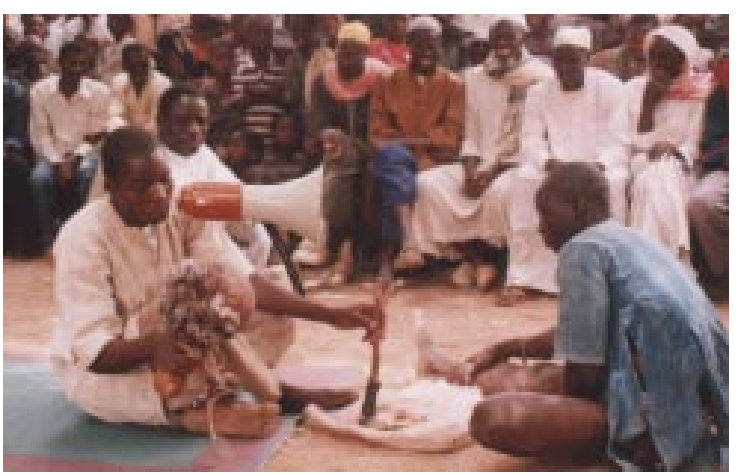

A scene from a skit during an inter-village meeting identify community decision makers for the programme. A date was fixed with each village delegation to hold a general assembly for orientation and discussion with the entire village.

\section{Example of a skit used to introduce programme objectives}

\section{Objective}

To encourage villagers to discuss the value of a basic education programme by using the example of the village of Laafibala. (The play takes place in two scenes with three actors).

\section{Scene I}

Ousmane is an adventurous man who left his native village of Laafibala long ago. He now returns to Laafibala and discovers there have been many changes. The village is clean, the health and educational infrastructures are well maintained. In his opening commentary, Ousmane notices that there are many women going for services at the health clinic. He also notes that the old dumping ground, once full of garbage, has become an attractive area where children play and people meet to discuss. He is filled with wonder by all these changes. He goes to his childhood friend, Tiraogo, who never left the village, to find out what happened.

\section{Scene II}

At Tiraogo's home, Ousmane is received with great joy. Tiraogo's wife gives him some water then turns to go back but Tiraogo tells her not to leave because they (both) have a visitor; this shows an effort to integrate women into family affairs. After greetings, Ousmane inquires about the changes that he has noticed in the village. Tiraogo and his wife explain to him that the inhabitants of Laafibala have benefited from a communitybased intervention programme. It is very important to emphasize the programme philosophy, its goal and objectives. They discuss the themes developed in the class sessions such as human rights, the problem-solving processes, hygiene and women's health. Tiraogo and his wife explain to him that it was the knowledge acquired during the class activities that allowed them to undertake important action towards development of the community and advancement of women. Ousmane, very happy about the new developments in his village, asks his friend to enrol him in the class so that he too can benefit from the same education. With that, he leaves.

\section{Questions for discussion:}

1. What has happened in the village of Laafibala?

2. What theme is developed in the skit?

3. How has the village of Laafibala developed itself?

4. How did the village of Laafibala organize itself?

5. What allowed for changes in the village of Laafibala?

6. Does your village want to be like Laafibala?

7. What are some of the objectives of your village? 
vi) General village assemblies to present and discuss the programme

In each of the 23 villages, men, women and children participated in a general assembly for the presentation of the programme. During these gatherings, the participants discussed the content and objectives as well as their responsibilities relating to the programme. These were the same issues discussed during the meeting with the community leaders.

The larger meetings held in each village aimed at reaching as many people as possible. About 2,071 people (841 women, 1,005 men and 225 children) took part in the meetings. These meetings also allowed project implementers to get feedback on people's expectations as well as their reactions to the general programme and the responsibilities required by the villages choosing to accept to participate.

vii) A feedback meeting with the village representatives

A smaller meeting with representatives from the village was held at each health clinic after the village meetings. Each village delegation evaluated the village general assembly. Special issues raised by villagers were debated.

Each delegation officially expressed its commitment to the activities of the programme. This act constituted a voluntary acceptance by the villagers to participate in the programme and to respect their role and responsibilities during the implementation phase. This was the first step towards the sharing of responsibilities.

\section{Organisational phase}

The organisational phase consisted of all the activities undertaken in each community to prepare for the programme. The activities implemented during this phase were:

\section{i) Creating Village Management Committees}

A Village Management Committee is the most important structure in the implementation of the TOSTAN programme in the village. It plays an intermediary role between the class participants, the villagers and the programme. To establish the Village Management Committee in each village, the leaders of each village:

- Analysed the role of the committee,

- Established clear and precise criteria for selection of committee members,

- Determined the skills needed to ensure proper functioning of the committee.

\section{Criteria for the selection of members of the Village Management Committees}

- Available to spend time working in the committee

- Honest

- Dynamic and interested in working for the common interest

- Able to defend the interests of the village

- Respected and polite

- Loves to work and knows how to forgive

- Good social skills (gets on well with others, is diplomatic, is able to exercise authority, is mature)

- Knows how to read and write in Mooré, the local language

- Is not frequently absent, and is able to travel when required

- Is concerned about public affairs

In addition, committees should include young and old members as well as representatives from all neighbourhoods of the village. 
Altogether 23 Village Management Committees were established including 44 women and 154 men.

\section{Tasks of the Village Management Committees:}

- Receiving and managing all materials and supplies for the class

- Maintaining the class and the supplies

- Motivating people to participate in the education programme

- Organising activities outside the classroom with other participants

- Organising village and inter-village meetings

- Solving problems and conflicts that arise

- Giving advice on the contents of the programme

\section{ii) Identification of the criteria and choice of participants}

The participants are the people who attend the classroom sessions on a regular basis. To select participants, the members of the Village Management Committee and the leaders in each village met to reflect on the programme and on what the improvement of knowledge, through the participants, could bring to the village. The discussions resulted in setting basic criteria for the selection of a group of candidates capable of leading innovation in the community.

Initially, the education programme implemented in Senegal did not have classes for men. However evaluations conducted at the end of the programme revealed that, for better mobilization and understanding of the new issues emerging from the programme, men needed to be more involved in the classes. This was also crucial in the Burkina Faso context where several studies on Female Genital Cutting have showed that men are crucial in the decisionmaking process. Guided by these arguments, Mwangaza decided to take gender into account and integrated men into the programme. Members of the Village Management Committees, in collaboration with the area leaders, were given the mandate to come up with a list of participants based on the criteria for selection. A list of 30 men and 30 women was requested from each centre for a total of 1,380 participants. However, at the conclusion of the selection process, 636 women and 625 men were enrolled in the 23 villages, for a total of 1,261 participants.

\section{Implementation phase}

This phase included all the training activities for community facilitators and Village Management Committees and implementation of educational activities at the community level.

\section{i) Training for facilitators in Mooré transcription}

TOSTAN and Mwangaza Action have a philosophy of using the national language of the community in which they work. In order to ensure that facilitators were capable of reading and writing in the Mooré language, Mwangaza organized a six-day training session for the 23 community facilitators. This session allowed them to master the rules of transcription in Mooré, the major language in Zoundwéogo Province. During the training session, the following aspects were studied:

- Presentation of the international alphabet and the Mooré alphabet

- Essential rules for transcribing Mooré correctly

- Presentation and reading of numbers 
- Study of long and short vowels

- Study of long and short nasal vowels

\section{ii) Training for facilitators on educational methods}

Two training seminars based on the TOSTAN training model were organized for community facilitators. An interactive approach was used for the sessions, which involved both theory and practice.

\section{Training seminar for Modules 1 and 2}

The community facilitators recruited were new to the field of development. To ensure they were well prepared, Mwangaza used the TOSTAN Facilitator's Guide for Modules 1 and 2 and introduced participatory methods for implementing the first cycle of the community based education programme. The first three-week seminar included the following themes,

- Human rights education

- The problem-solving process

- Techniques for facilitating class sessions and discussions

- Techniques for using illustrations

- Adult education

- Techniques for organizing and conducting class sessions

Training seminar for Modules 3 and 4

A second training seminar was organized for the second cycle of the programme. The three-week seminar focused on enabling the facilitators to use the TOSTAN Facilitator's Guide for Modules 3 and 4 presenting sessions on hygiene, disease prevention, women's health and violence against women. Other topics such as maternal health and the Burkina Faso national policy and strategy on vaccination were also discussed. The second seminar contributed to improving the community facilitators' knowledge of:

- Reproductive anatomy and physiology

- Traditional practices harmful to women's health

- STIs and HIV/AIDS

- Vaccinations for women and children

- Actions to reduce maternal mortality

- Review of the overall programme strategy

- Information on organization of the health system in Burkina Faso

The points discussed during the seminar strengthened the community facilitators' knowledge of the contents of Modules 3 and 4 and contributed to effective guidance of the education programme activities in the villages. The residential seminars and congenial atmosphere motivated participants to continue work after normal hours which greatly helped the facilitators better master the management of their future classes.

Besides the regular training from the Mwangaza team and TOSTAN trainer, the participants had access to other resource specialists concerned with human rights and governance, family, health and traditions. Their presentations and ensuing discussions helped to reinforce their knowledge and understanding of the issues.

Each community facilitator received the following materials before leaving for the village:

- TOSTAN educational guides for implementing each module (in French and in Mooré) 
- Flip chart paper for session preparation

- A flip chart presentation on human rights published by TOSTAN

- A gas lamp

- Illustrations for sessions of Modules 1, 2, 3 and 4

- Class registers and notebooks for class activities

- A portable bed and office supplies

\section{iii) Meeting between the committee members and the village facilitators}

It took two months to establish and train the Village Management Committees before starting the educational sessions of Module 1. In order to begin activities in the field, a work session was held in each village between the committees and community facilitators to:

- Agree on a location for the classes

- Decide what equipment was needed (chairs, tables, mats, etc.)

- Decide if further recruitment of participants was necessary

\section{iv) Training of Village Management Committee members}

A two-day training session was organised for the members of the Village Management Committees. The session focused on the role and responsibilities of the committee members and on improving their management skills.

\section{v) Equipping the villages}

It was important to provide a certain amount of classroom equipment in order to ensure a minimum of comfort for learning in the villages. The programme provided the following materials and supplies for each class:

- Six benches

- A clothesline for hanging illustrations

- Some clothespins

- A notebook and pencil for each participant

vi) Determining practical modalities for starting sessions in the villages

A work session took place between the community facilitator and the participants. This first class meeting allowed the men and women's classes to exchange ideas about the practical modalities for starting up the educational programme. As a group, they chose the days and hours that best suited the majority of the participants in view of their own work schedules. It also provided an opportunity to review the main themes of the programme.

\section{vii) Conducting the village classes}

The community facilitator followed the schedule determined by the participants and began Module 1 in February, 2001. The sessions on human rights and the problem-solving process were held every other day to allow time in between classes for assimilation of themes and sharing of new information with other members of the community. The participants implemented session activities both in the class and in the village. Participatory techniques such as dance, song, role-play, poetry and small discussion groups were

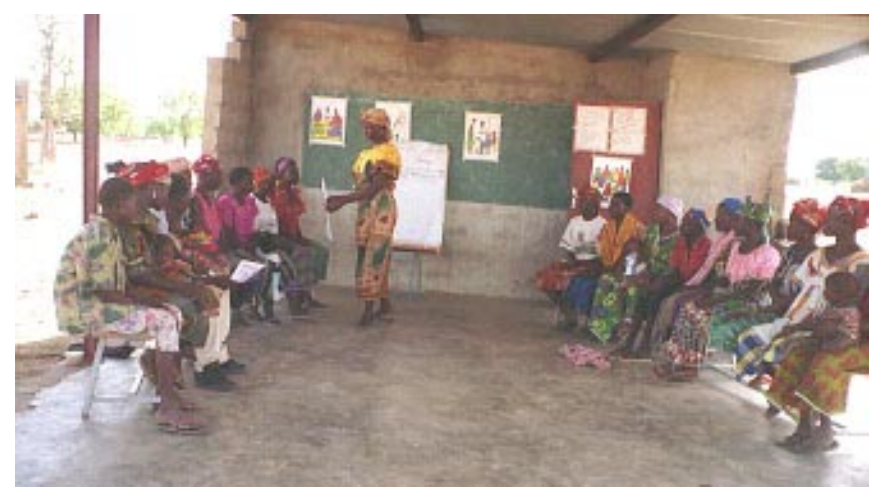

Educative sessions on human rights with the audience both (male and female) in Noghin village (Binde district) 
used to ensure that the learner always remained at the centre of the educational experience. During the class sessions, participants always sat with chairs placed in a semi-circle, an arrangement that facilitated eye contact and lively discussion. The facilitators sat with the participants to emphasize that they were also learners. This broke with the model often followed by teachers in the formal education system who stand in front of students and present a lesson rather than facilitating a discussion. The facilitator started the class by presenting the session number, title and objectives on flip-chart paper. The facilitator always prepared the session on note cards to guide him/her through the activities for the day.

Every session concluded with a brief evaluation in order to review the objectives of the day and the results achieved.

The 64 sessions of the TOSTAN education programme were carried out over two cycles. The first cycle ran from February to May 2001 and included human rights education and the problem-solving process. The second took place from December 2001 to March 2002 and included hygiene, disease prevention and women's health.

\section{viii) Presenting public sessions}

As the participants attended classes, they also organized public sessions in collaboration with the facilitator to inform other nonparticipating community members of information learned in the sessions. These public sessions were organised both in the project villages and in other surrounding villages. The sessions covered the following topics:

- Female Genital Cutting

- Pregnancy and Family Planning

- The right to health

- The right to a healthy environment

- Sexuality

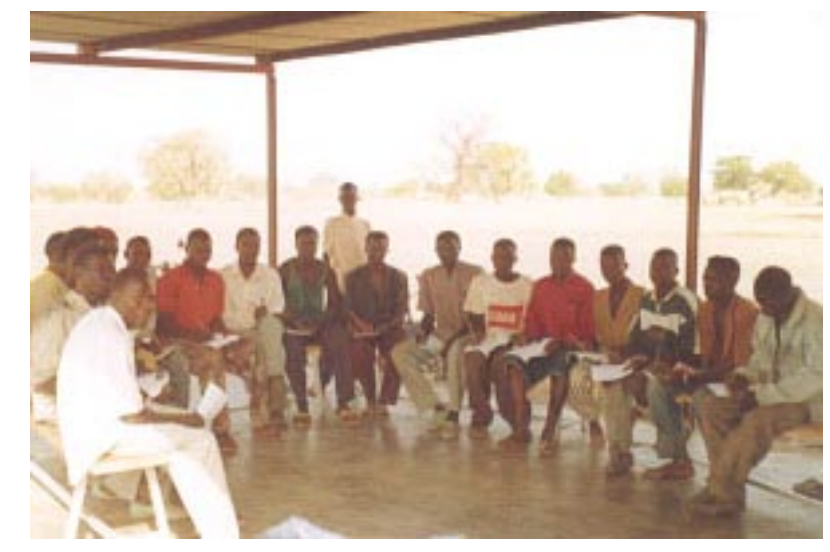

Session on problem solving with the participants of Nacombgo village (Béré district)

- STIs and HIV/AIDS

In participating villages, the idea was to inform everyone about new ideas being discussed by class members in order to involve them in the decision-making process. The villages that were not covered by the programme were also given information so that they could support the strategies the 23 participating villages developed. Everyone greatly appreciated these public sessions.

\section{Social communication}

During large public meetings, villagers sharing the same health centres met and exchanged ideas and information.

\section{Village Meetings}

Class participants and the members of the Village Management Committees organized village meetings in each of the 23 villages to inform everyone of class

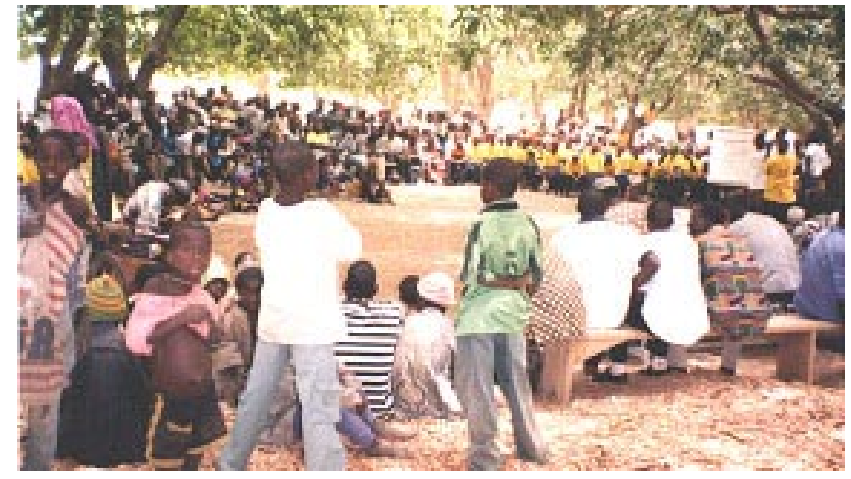

Inter-village meeting between delegates from five villages in Sondré (Béré district) sessions and activities. Class themes, along with strengths and weaknesses, were discussed and solutions proposed to the problems identified. 
The presentation was done with the aid of songs, dances, sketches and speeches. A total of 6,500 people took part in these village meetings, which served as excellent preparation for the inter-villages meetings. Each village identified and presented their feedback at the meetings.

\section{Inter-village meetings}

Villages sharing the same health centre (about eight villages per centre) met at the end of both cycles. During these day-long meetings, representatives from each village exchanged ideas about new information learned and activities implemented as well as pointing out strengths and weaknesses of the programme

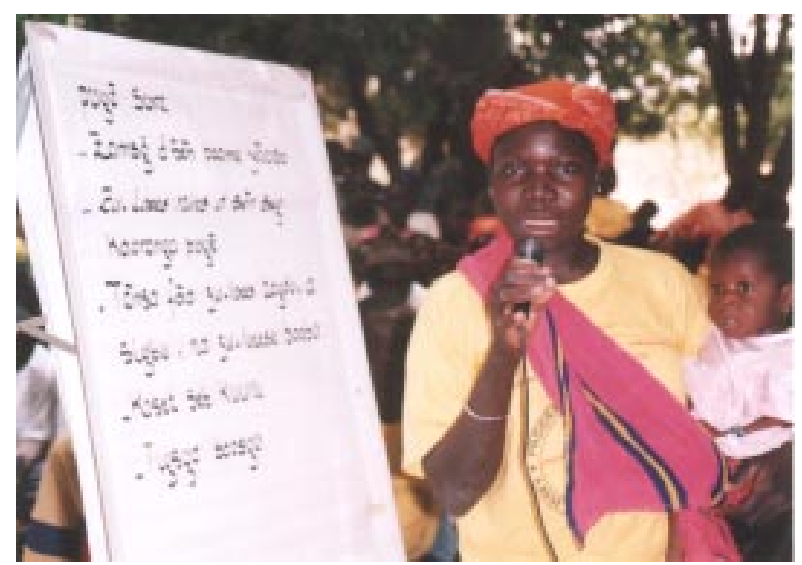

At the Sondré inter-village meeting; a female member of the Signoghin village class presents the problems that her village wants to solve with the community leaders, development and administrative partners who attended. The participants also discussed and proposed solutions to problems that were common in all the villages. Six inter-village meetings were held. The first three were held at the end of the first two modules and the last three, at the end of Modules 3 and 4.

The meetings held after the first training cycle demonstrated the need for other members of the community to participate more in the activities of the education programme in order to reinforce the results. The second meeting put more emphasis on the urgent need to fight against violence against women, with a particular emphasis on the need to end the practice of Female Genital Cutting. About 800 people participated in this second meeting.

\section{Supervision and evaluation phase}

At the beginning of the programme, the supervisor scheduled visits to the village to support start up activities in each village. The project supervisors had the role of supervising classes, facilitators and other class activities. Each supervisor had responsibility for a maximum of eight community facilitators and centres. During the monthly meetings in each zone, each facilitator presented his/her activities along with the monthly action plan.

At the village level, Village Management Committee members coordinated and followed through on activities, maintaining regular contact with the supervisor. The training teams also held monthly meetings to review progress and activities implemented as well as to discuss solutions for any difficulties encountered.

Formative evaluation of the programme was continuous. Also, evaluations were undertaken during the sessions and at the end of each module.

\section{Community Changes}

During the implementation of the programme, Mwangaza staff noted positive reactions to the educational programme sessions in most of the villages. These reactions were spontaneous and diverse. They included identification and implementation of concrete actions resulting from the discussions held in the classes. These actions began slowly at first particularly within three villages and then spread to the rest of the 20 villages. The project developed a system to disseminate positive village experiences to encourage greater activism.

The activities implemented in the different villages were discussed during class sessions. These experiences gave new ideas to other classes and constituted a source of motivation and 
inspiration. It encouraged participants to implement actions in their own communities so that their experiences would also be shared with others. The first actions undertaken were:

- Cleaning up of public areas (dispensaries and schools)

- Denouncing cases of violence and discrimination (battered wives, children not going to school).

Soon many other important activities were initiated by the participants, all important for community development. These activities can be categorized as follows:

\section{Cleaning and beautification of public places}

- Building more than 89 modified wood stoves

- Cleaning wells and water sources in all 23 villages

- Cleaning markets

- Cleaning the village chief's compound and the local police station

\section{Health promotion}

- Cleaning of health centres and social advancement centres (dispensaries and maternities)

- Renovating 10 primary health centres

- Producing plays on women's health

- Instituting public health days in the 23 villages

Twenty-seven public sessions were held in the villages on the following topics: hygiene, FGC, sexuality, family planning, STIs and HIV/AIDS, pregnancy and vaccination. In addition, twenty-three groups for the promotion of health were established in each of the 23 villages.

\section{Promotion of human rights}

- Denouncing forced marriages

- Discussions on violence against women within the 23 villages

- Establishment of 684 birth certificates

Establishment of 78 family record books

- Establishment of 693 identity cards

- Communal marriage celebrations for 43 couples.

Sixty-nine people participated in a workshop on gender-based violence. A case of discrimination related to children's education was noted.

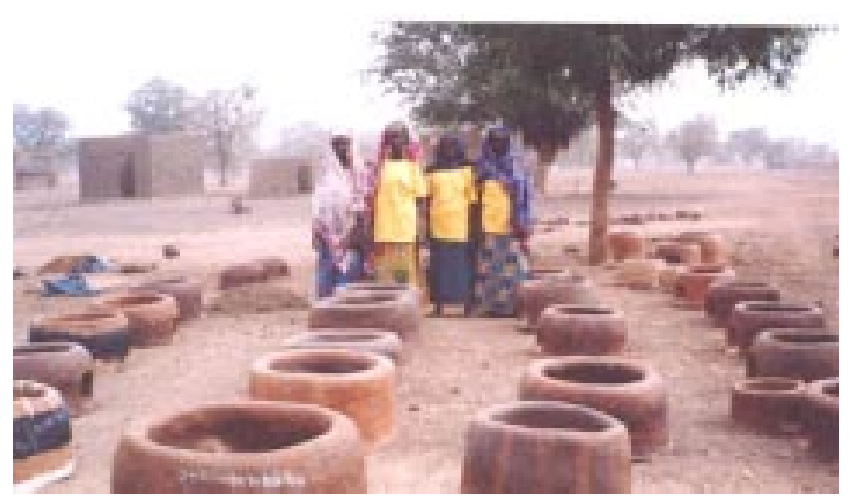

Female participants from Kondrin Village in front of the adapted wood stoves they constructed

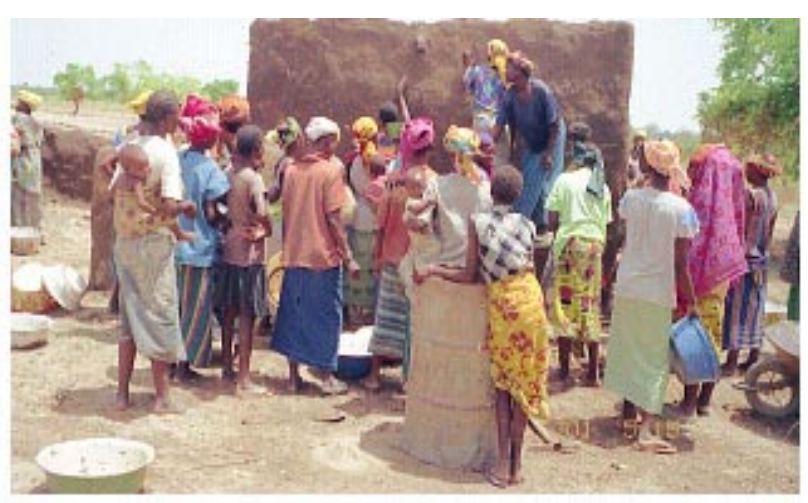

Women from Yorgho villagein the process of building walls of the primary health center

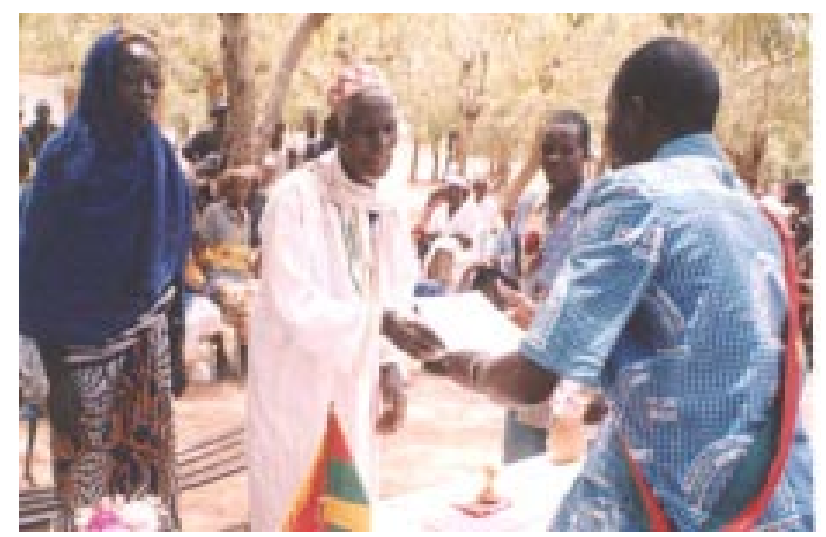

Public marriage ceremony in Bere; A female member of the audience and her husband receive their family record book after formalization of their marriage 
These actions are proof of the changes occurring in the communities and they demonstrate the acquisition of knowledge by the participants and their spouses.

\section{Programme Results}

\section{Improvement of people's knowledge}

The different evaluations conducted during and after the modules of the education programme show a significant increase in knowledge related to the content of the four modules by participants, their spouses and the friends with whom they shared information. The actual number of people trained was 1,674 (907 women and 767 men), with an average of 73 participants per village.

\section{Community actions in the villages}

Another positive result of the programme is the development of concrete actions within the community by participants in collaboration with the rest of the village. The actions undertaken focused on improvement of health and the standard of living, and promotion of human rights in general and those of women and children in particular. All these actions resulted from awareness-raising and increased knowledge.

\section{Social communication on violence against women}

Discussions of violence against women and girls such as female genital cutting and early forced marriages and birth spacing were no longer taboo. The women discussed these issues openly with the men and the community leaders. This was reinforced further by the organization of a community workshop on violence against women. Sixty-nine people from the 23 villages met and exchanged ideas on common problems in the community. Community representatives were able to evaluate the status of sexual and reproductive health. The tools and techniques used included Gantt diagrams. The villagers identified the health problems and analyzed them in order to find causes and appropriate solutions.

A common action plan among the 23 villages was developed to seek solutions to the following problems:
a) Birth spacing
b) The practice of female genital cutting
c) The practice of forced and early marriages
d) The spread of STIs and HIV / AIDS
e) Violence against women
f) Low literacy levels

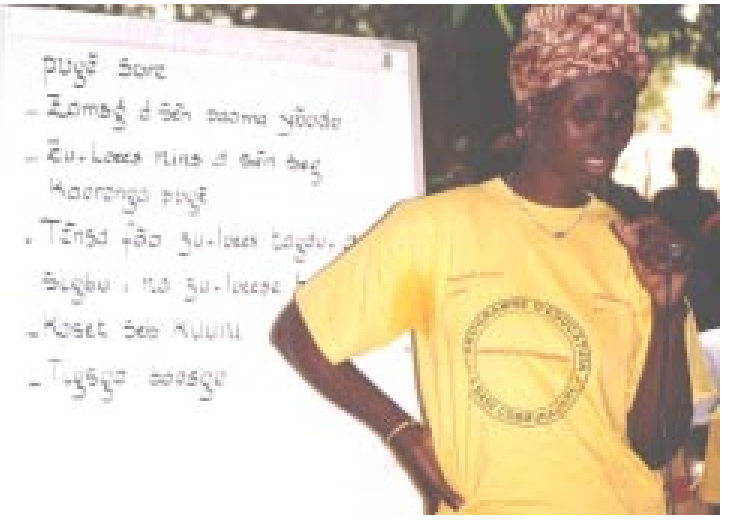

A female participant from Nacombgo presents lessons learned from the programme at the intervillage meeting in Sondré

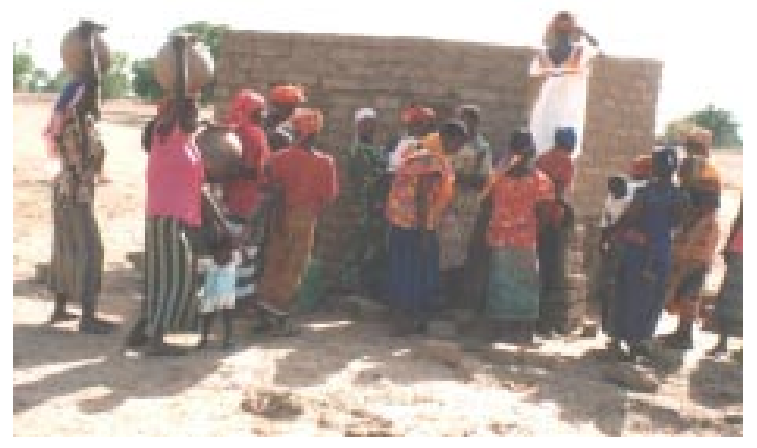

Women from Doue Taking part in the construction of a primary healthcare center in the village

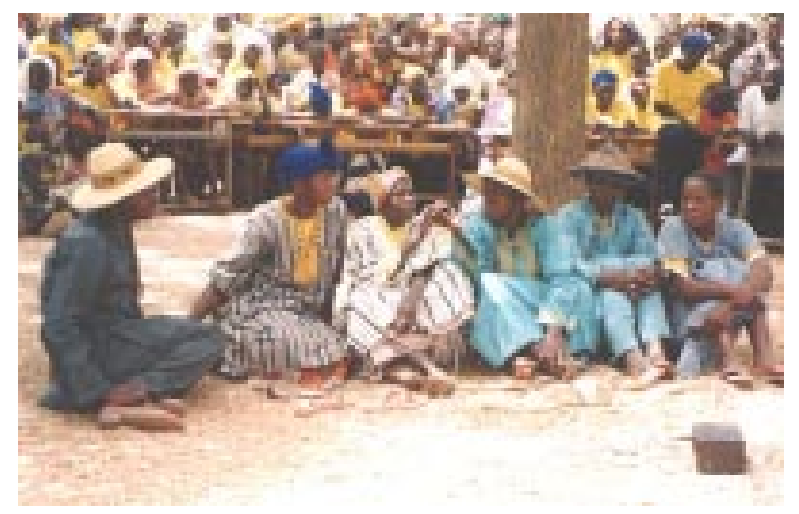

A play on HIV/AIDS presented by the participants from Siguivousse during an inter-village meeting between 11 villages in Béré 
Below are some of the comments from the population showing evidence of the changes their communities experienced.

"Your teaching enabled us to get along better with our wives. Our relationships have been simplified. It is for this reason that the men asked that certain sessions be done over for their spouses." (Male participant, Signoghin village, Béré district)

The participants now better understand women's health problems:

"Your teaching on health allowed us to know about our bodies and learn about contraceptive methods. " (Female participants, Sondré Village)

"Your teaching freed the women to speak out. Now they are able to talk with confidence." (Sponsor, FARD NGO)

"There has been increased use of health services for prenatal consultation, treatment and childbirth." (Head nurse, Centre of Health and Social Promotion Bindé)

"There is new respect for women. More and more, women are consulted in the decisionmaking process and allowed to propose solutions. Before only the men did this. " (Participant, Béré Village)

"There is more involvement of traditional leaders in the fight against Female Genital Cutting and birth spacing." (Female participant, Kondrin village, Béré)

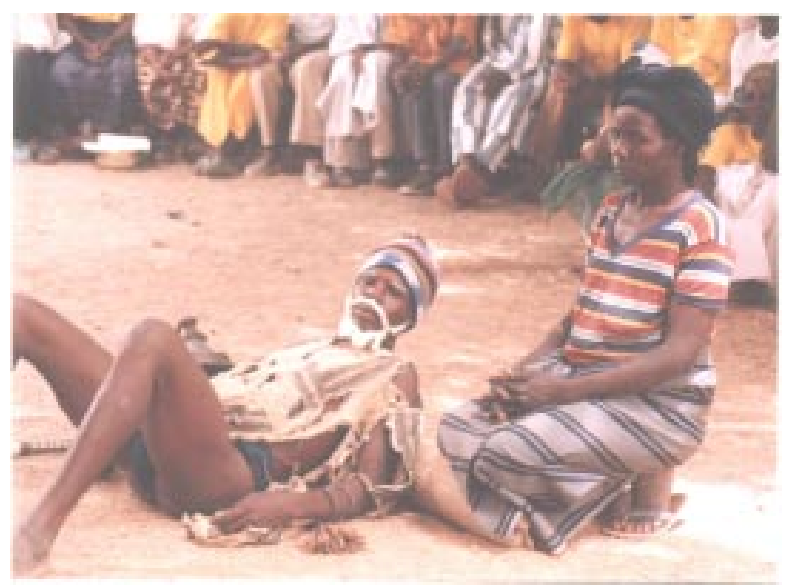

Male and female participants in Bindé present a play on the negative consequences of female

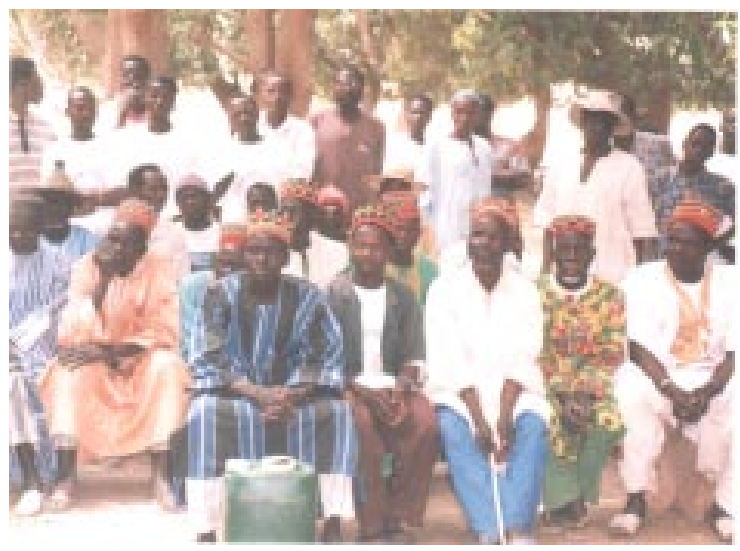

Participants who attended the inter village meeting in Sondré possible

\section{Agreement of 23 villages witnessed by 5,000 PEOPLE}

To undertake a collective agreement to end an important social convention is an act of great importance in the process of behavioural change. The Bindé and Béré populations made this collective decision on May 3, 2003. About 5,000 people took part in the ceremony to declare the abandonment of Female Genital Cutting.

The importance of this act can be seen on two levels. On the

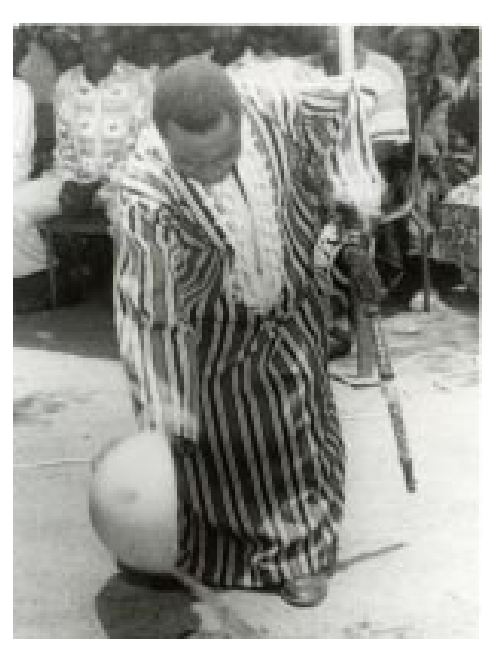

Through this ritual action, this man was given a mandate to support, in the name of their ancestors, the action taken by the women of Béré to abandon Female Genital Cutting community level, a commitment was made to abandon the practice of Female Genital Cutting. For the Béré and Bindé people, it was a significant turning point. They made the historic decision to end the ancestral practice and to promote the health and human rights of 
women and young girls. The act of taking a position in public showed that they had assumed their responsibility and are extremely courageous. They took the time to understand and, fully aware of the consequences, acted to collectively abandon the practice of FGC. The media greatly contributed to spreading the important messages of the declaration throughout the nation. This act by the Béré and Bindé people became a model for other communities in Burkina Faso who are seeking to end FGC.

\section{A Public Declaration to Abandon Female Genital Cutting, Béré, 3 May 2003}

The people of 23 villages from Béré and Bindé announce our decision to put to an end today, the practice of Female Genital Cutting in our community.

In Burkina Faso, there are few communities who do not practice female genital cutting. The people of Béré and Bindé did also practice FGC for the following reasons:

- we thought it was good for our children

- we were not educated

- we ignored the negative health consequences of this practice

- we had no information on our bodies and the functions of the body

- we ignored that everyone has human rights and has the right to make decisions about his/her body

Dear guests, in the past 2 years, the situation in our community has changed. Yesterday we lived in darkness; today we have seen the light thanks to the education programme implemented by Mwangaza. Thanks to this programme, we are now able to clearly see certain problems that formerly caused us much suffering.

We now know that even though FGC is a traditional practice, it is dangerous for the health of women and girls. We also understand that there are human rights, which ensure the right to health and bodily integrity.

We know that it is important to promote health and human rights in our communities.

In light of all this, and fully conscious of our decision, we would like you to bear witness to our commitment:

We the people of 23 villages from Béré and Bindé, do solemnly commit to undertake actions for the promotion of health and for the respect of human rights in our community. Consequently, on this date, May 3, 2003, we have decided to put an end to the practice of female genital cutting in all our villages.

Thank you.

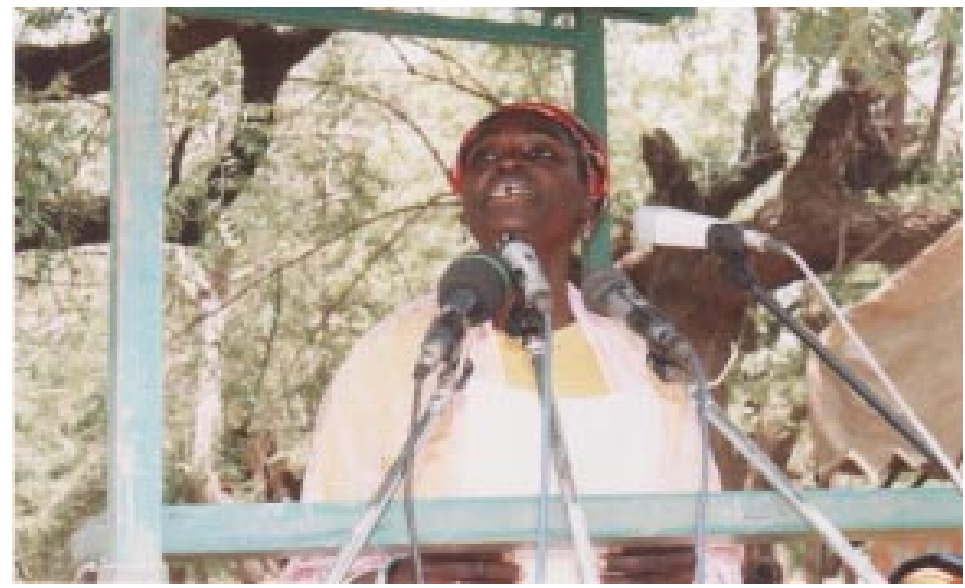

This woman standing a the special podium, calls out the names of all the communities taking part in the public declaration ceremony at Béré 


\section{Underlying factors for social change in the Béré and Bindé Communities}

The process, which was followed in the Béré and Bindé communities to publicly declare the abandonment of Female Genital Cutting, consisted of the following steps:

\section{Workshop on problem-solving}

The knowledge acquired by the 23 villages through the community education programme led them to fight against common problems which include violence towards women, forced and early marriages, illiteracy, lack of family planning, increase of HIV / AIDS and the practice of FGC. Representatives from the 23 villages listed the problems, analyzed them and discussed possible solutions. This workshop was the first meeting of people working towards collectively solving these types of problems. Both men and women participated in this workshop as well as traditional and religious leaders who are influential in changing attitudes within the community in relation to habits and behaviour.

\section{Exchange visit to Kolda, Senegal}

TOSTAN felt it was essential for programme participants to witness a public declaration ceremony to understand the importance of such an event. Thus, TOSTAN funded a delegation of three participants and the project coordinator from Burkina Faso to travel to Senegal to participate in a public ceremony for the abandonment of FGC at Karcia $(30 \mathrm{~km}$ from Kolda) on June 5, 2002. This public declaration was made by a total of 300 villages who openly announced their decision in a positive and joyful celebration. Amongst the participants were members of the Network for Population of the Senegalese Parliament.

During the visit, the Burkina Faso team exchanged ideas with Senegalese participants and facilitators concerning the education programme and how it helped to support women's health and rights.

This exchange visit reinforced the delegations' commitment to the promotion of health and human rights for women and girls.

\section{Intercommunity dialogue}

The participants and members of the delegation that visited Senegal talked with members of their communities when they returned to Burkina Faso (traditional leaders, government leaders, religious leaders and the population in general) to share their experiences from Senegal and to review knowledge and skills gained through the community-based education programme.

Several village meetings and inter-village meetings were held within the framework of intercommunity dialogue. These meetings involved large numbers of people, with the aim of making agreements to abandon FGC in all 23 villages. Each village made its own agreement and then agreements were made among villages at meetings held at Béré and Bindé.

The communities' agreement to end FGC was made in front of civic leaders and representatives of NGOs active in Béré and Bindé. The success of these activities bears witness to the people's commitment to promoting the health and rights of women and specifically to the abandonment of FGC.

\section{Workshop to plan activities towards the public declaration of abandoning FGC} A workshop was organized to plan how to make the decision publicly official. The workshop brought together representatives from the 23 villages as well as observers and administrative leaders from Béré and Bindé. 
The workshop's aims were:

a) To exchange ideas among village representatives concerning the practical aspects of the communities' decision to abandon FGC.

b) To identity and plan activities to make the agreement public and official. The discussions focused on what it means to make a public declaration and give one's word of honour in the Béré and Bindé communities. Thus, the procedures for a collective agreement and mechanisms for follow through on the decision were discussed.

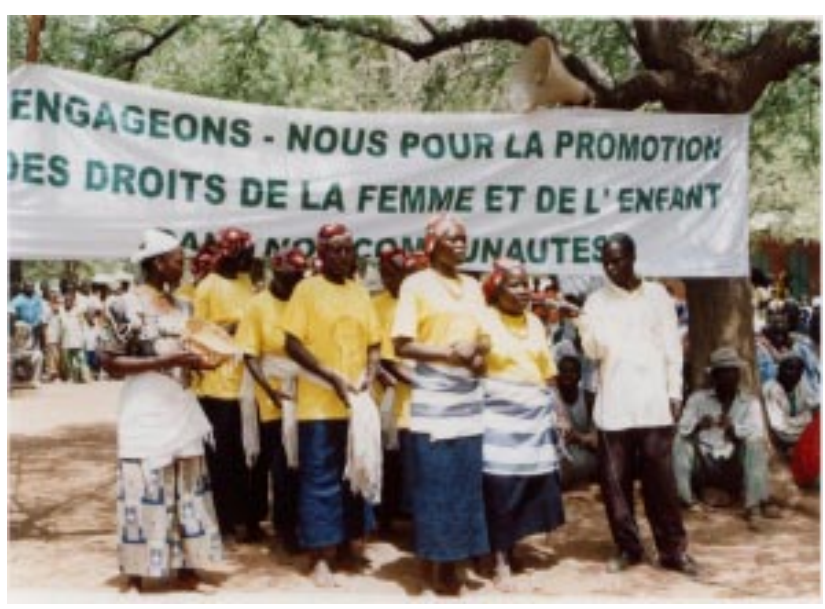

This group of women sang a song calling for the abandonment of Female Genital Cutting in all communities during the public declaration in Béré

Amongst other decisions made at the workshop, it was agreed that a spokesperson for the women would present the Béré and Bindé collective agreement. She would be followed by a representative of the traditional leaders in a symbolic gesture of support from the two districts.

\section{What can be learned from this collective agreement?}

\section{Women's determination is key}

In the fight against violence and for the promotion of their reproductive rights, the women from the two districts were mobilized from the beginning of the programme. As the victims, women resolved to end this violence. During programme implementation, they were always at the forefront to demonstrate their determination to stop Female Genital Cutting, and to promote the well being of their daughters. The women did not spare any effort in this fight. They braved bad weather, heat, and covered long distances on their bicycles to take part in community meetings so that women's needs could be taken into account in major decisions in the community.

\section{Involvement of men and leaders}

Men in the villages supported the women in the fight for better health for their daughters. Men, and leaders in particular, showed intelligence and vision in the fight against FGC. They responded positively to the appeal for actions in favour of women. Traditional and religious leaders supported recognition of women's rights and health.

\section{Media mobilisation}

The media played a critical role in publicizing the declaration. In Béré, this unique event received important publicity, and it was reported throughout Burkina Faso and beyond. The national and international press published ten articles before, during and after the public declaration ceremony. The Burkina Faso National Television (TNB) carried two news stories about the event during its peak hours on the evening news. Burkinabé National Radio (RNB) also covered the event in several programmes. The information was broadcast in the main languages of Burkina Faso: Mooré, Dioula, Fulfuldé and Gulmancema.

The TOSTAN programme considers media as one of the pillars in its strategy for social mobilization. However, the distinctive characteristic of the approach adapted by Mwangaza and Population Council was in the implementation and adoption of a plan specifically for the Burkinabé media scene. Implemented in 3 phases, this plan aimed to brief journalists on the sensitive character of FGC in Burkina society, before winning their agreement to report on the 
event. Considering the limited budget, it was vital to convince the media of their social responsibility.

Courtesy calls were paid to all the newspapers, radio, and television directors to brief them on the event and the need for their support. The meetings were fruitful and due to the support given by Pop Media Burkina - a network of journalists interested in population issues, all the leaders of Burkinabé media houses were brought together. After agreement was reached with the media, visits to make contacts and provide information were organized for editorial staff from different organizations. A lunch meeting three days before the ceremony brought together 18 journalists who were to cover the event. This pre-declaration coverage was not only an opportunity to sensitize journalists using a panel of experts in reproductive health, but it also contributed to creating an atmosphere of confidence among the journalists and other participants.

\section{Difficulties ENCOUNTERED}

Some of the main difficulties encountered during the implementation of the programme are discussed below.

- Unforeseen costs: In Senegal, TOSTAN had quality facilitators available for the programme at the local level. However, in Burkina Faso, Mwangaza had to recruit community facilitators capable of mastering the content of the curriculum in both French and Mooré. They were not from the villages where the programme was to be implemented and Mwangaza was faced with extra, unforeseen costs in recruiting people from outside the community.

- Delays: A delay occurred in the beginning of the programme due to administrative procedures in signing contracts with the donor. Initially, the programme was intended to last for one continuous period from January through July; however, the programme began after a 4-month delay in the middle of the dry season and, as a result, the participants only had three months to study before a pause for rainy season farming activities. The second part of the programme had to be postponed until the following year when participants are available to study.

- Keeping facilitators in the programme: Some of the facilitators quit during the rainy season pause since they were not paid during this period and had to search for other employment. Mwangaza had to replace them with new facilitators in order to continue the project. The loss of these experienced and trained facilitators disrupted normal programme progress.

- Class attendance problems: Some social events (baptisms, marriages, funerals), which occurred when the classes were in session, disrupted the programme because of numerous absences and sessions had to be repeated, causing inconvenience to facilitators in the preparation and teaching of the sessions.

- Lack of tangible incentives such as small income generating and micro credit projects to motivate programme participants was frequently mentioned as a drawback. This led to a lack of interest in certain topics and irregular attendance.

\section{LESSONS LEARNED}

The positive results from the programme led to reflection on lessons learned concerning community involvement in promoting reproductive health and development activities. 


\section{Involving leaders in the programme before implementation}

The presentation of the programme to the leaders of each community was the first step in implementing the community based education programme. This enabled the project to gain their support and participation, crucial for mobilising the rest of the community throughout the programme. Important decisions were always discussed with leaders first and they were included in dissemination activities.

\section{An immersion visit to the villages for the programme staff and facilitators}

In implementing the community-based education programme, Mwangaza recruited young people as community facilitators to carry out the activities in the communities. Many of these community facilitators had no experience with villagers because they had spent most of their lives in large urban centres. An apprenticeship and adaptation period was thus necessary to enable them to better collaborate at the village level. This gave the facilitators the opportunity to become more familiar with the community with their values of trust, mutual respect, simplicity, and tolerance, all crucial for working with village populations.

\section{Living in the village to establish trust}

One aspect of programme philosophy is for the facilitators to live in the village to be closer to the people and part of the development process. Thus, the whole team of 23 facilitators and 3 supervisors stayed in their respective villages whenever classes were in session. This allowed for trust to develop between the community and the programme agents. The programme personnel and community learned to understand one another and to speak the same language.

\section{Using the local language and the participants' mother-tongue}

The language used in the programme zone was Mooré. The community facilitators who were recruited were either Mossi or people who could communicate easily in that language. In order to put everybody on the same level, a seminar dealing with the transcription of the Mooré language was organized. The one-week seminar allowed the facilitators to study rules for transcribing Moore and to improve their vocabulary, especially related to the programme themes.

This action was beneficial in thatas the programme was perceived as a post literacy strategy. Because the facilitators always spoke and wrote in Mooré, it motivated the already literate participants to express themselves and stimulated a desire to learn to read, write and do math among the non-literate participants.

The participants who were already literate took notes during the sessions. We even noticed that participants who missed a class would give their colleagues their notebooks so they could know what happened during the session. Those who were not literate were motivated to register in a literacy centre.

\section{Learning through experience}

The TOSTAN educational approach consists of alternating training for facilitators with teaching in the field. In this way, the entire content of the guides is not taught during the same training and allows the facilitators time to assimilate the sessions.

This interactive process allows the facilitators to acquire knowledge, apply their new skills and learn lessons in the classroom and community before receiving new knowledge.

Based on the model of experiential learning, this allows for the correction and improvement of strategies before the next training session. The facilitators were first trained on teaching 
methodology and facilitation techniques as well as the content of Modules 1 and 2 (Human Rights and Problem Solving). After this 3 week training, the facilitators went to their village to teach the sessions.

A mid-programme evaluation took place at the end of the first modules, followed by a second training seminar on Modules 3 and 4 (Hygiene and Women's Health). All this ensured that the facilitators and participants understood programme content before undertaking the next training modules.

\section{At least 18 months to get results}

Initially, the teaching of Modules 1 - 4 was intended to last only 7 months, the period of one dry season. However, because there was a delay in getting programme activities underway, it was only possible to implement Modules 1 and 2 by June. The need to stop the programme during the rainy season and start up again the following October led to increased costs and the loss of many facilitators who could not wait 4 months to begin teaching again.

During this period, the participants reviewed sessions, had time to assimilate content and shared and applied the new knowledge covered in Modules 1 and 2. Programme staff remained in contact with the villages through the supervisors who continued to work on implementing action plans that had been developed during the classes. However, in the future, Mwangaza believes it would be best to plan for more time for project implementation and include the rainy season. Behaviour change is a long process.

\section{Each community chooses those who will benefit from new knowledge}

One of the responsibilities of each village was to choose the people who were to take part in the programme activities. Each village set the criteria for recruiting their participants. The programme respected the decision made by each community, agreeing to its philosophy to honour decisions taken by its partners.

\section{Public sessions outside the classroom}

Certain sessions conducted in class were greatly appreciated. The participants asked for these sessions to be held outside the classroom so as to include the whole village.

The following themes were discussed during the public class sessions:

- FGC

- Family planning

- STIs/HIV/AIDS

- Sexuality and preparation for birth

These sessions allowed the men and women in the villages to understand the need to take concrete action to preserve the health of the people. Given the success of the public sessions, they were encouraged in all the villages.

\section{Active methods used to facilitate sessions}

Most of the participants in the programme were adults. Working with adults requires the use of appropriate methods. To achieve this, facilitators used active methods of learning characterized by:

a) Participatory learning: The individual learns better when personally involved in the activity.

b) Motivating participants: The individual feels concerned by and involved in the subject being discussed. 
c) The facilitator: The instructor is more of a facilitator and acts as a catalyst rather than a teacher in the traditional sense of the term. He/she is no longer the "authority figure" but rather another learner who facilitates a dialogue among others.

d) Evaluation: There are no longer "tests" but rather self-evaluation involving the individuals or groups.

The programme was carried out based on these principles. Song, dance, theatre and group work were used to bring about a real feeling of participation and involvement, also allowing the participants to remember important aspects of what they had learned.

\section{Ten sessions per month is the best way to encourage learning and action}

Conducting at most three class sessions per week and not more than 10 sessions in a month gave the participants the time to assimilate new knowledge and plan and implement activities within their communities. This arrangement suited the community, allowing them to carry out personal or collective activities without major constraints.

\section{Human rights education as the foundation}

The first module implemented in the TOSTAN programme is understanding human rights. This created a favourable environment for discussing all topics related to participants' daily experiences. This knowledge also contributed to developing a culture of action within the communities.

\section{CONCLUSION}

The TOSTAN community based education programme seeks to develop community-based strategies with the aim of promoting conditions for improving the quality of life of rural populations. During the implementation of this programme in Burkina Faso by Mwangaza Action, it became obvious that the four modules had a significant impact in the 23 participating villages. The level of involvement, as well as the enthusiasm and commitment shown by the people during programme implementation, aptly illustrate their interest in this experience.

The teaching of human rights and reproductive health, which were the foundations of the programme, brought revolutionary changes to people's lives using a participatory and interactive approach.

The contribution of the programme to the community is visible through the different actions and decisions of the communities such as development activities, hygiene and health promotion and the respect of human rights in general. All of the actors in this community experience now demonstrate a new level of awareness and an assimilation of programme content.

In implementing this programme, community participation is key to providing an appropriate context for objective problem-solving and finding the best solutions.

Human rights education, reinforced during the sessions on reproductive health, helped in liberating women from harmful cultural practices of which they are often victims. The idea of promoting gender by including women in decision-making and in the fight against practices harmful to their health was eventually accepted. Social solidarity became stronger between members of the same community and between neighbouring villages. 
In spite of the difficulties encountered during the implementation of the programme, we witnessed a marked improvement in the social conditions of the people in the areas concerned.

However, as is normal in all movements for social transformation, there was some resistance during programme implementation. Far from being insurmountable, the obstacles actually helped to better formulate and strengthen lessons learned from the experience. These lessons will help in adapting the process when replicating the programme in the future.

Prevention is "being in advance", "planning ahead" "avoiding". The public declaration to abandon FGC in Béré, the highlight of this educational experience, can be seen as an act of social prevention.

Through this event, the Béré and Bindé populations refused and denounced anything that goes against the promotion of human rights and women's health in their environment, including FGC.

The declaration by the Béré and Bindé populations is a message to all those who still hesitate to end FGC, indicating that they will be confronted with others who have resolved to end this harmful tradition. Aside from these determined women and men, they will also meet opposition from the ancestors who, through the ritual act by an elder at Béré, now support the abandonment of FGC.

The public declaration is an important step in the process of social transformation and can contribute to the end of the practice of FGC. 